\title{
Adherence and Associated Factors towards Antidiabetic Medication among Type II Diabetic Patients on Follow-Up at University of Gondar Hospital, Northwest Ethiopia
}

\author{
Mastewal Abebaw, Anteneh Messele, Mignote Hailu, and Fisseha Zewdu \\ Department of Nursing, University of Gondar, P.O. Box 196, Gondar, Ethiopia \\ Correspondence should be addressed to Fisseha Zewdu; fishomafi2@gmail.com
}

Received 7 September 2015; Revised 18 December 2015; Accepted 22 December 2015

Academic Editor: Ann M. Mitchell

Copyright (C) 2016 Mastewal Abebaw et al. This is an open access article distributed under the Creative Commons Attribution License, which permits unrestricted use, distribution, and reproduction in any medium, provided the original work is properly cited.

\begin{abstract}
Background. The prevalence of diabetes mellitus (DM) is rising worldwide and is more in the developing countries which unfortunately are already suffering from communicable diseases. The aim of this study was to assess adherence and associated factors towards antidiabetic medication among type II diabetic patients in University of Gondar Hospital, Diabetic Clinic, Gondar, Northwest Ethiopia. Methods. Institutional based cross-sectional study was conducted. Systematic sampling technique was used. Morisky Medication Adherence Scale (MMAS) scores were used for labeling patients as adherent or nonadherent. Data were entered and analyzed using SPSS version 20. To see the association of variables logistic regression with OR and 95\% CI was done. Results. A total of 288 study participants were interviewed with response rate of $100 \%$. The level of adherence was found to be $85.1 \%$. Factors found to be significantly associated with antidiabetic medication adherence were level of education $(\mathrm{AOR}=14.27,95 \% \mathrm{CI}=3.0,67.82)$, duration of diabetes $(\mathrm{AOR}=6.10,95 \% \mathrm{CI}=2.03,18.34)$, and knowledge about $\mathrm{DM}$ and its medications $(\mathrm{AOR}=28.05,95 \% \mathrm{CI}=$ $8.96,87.8)$. Conclusions and Recommendations. Large proportion of respondents in this study were found to be adherent to their antidiabetic medications. Level of education, duration of diabetes, and knowledge about DM and its medication were significantly associated with antidiabetic medication adherence of patients. Health education including adherence counseling to create awareness towards DM and its medications is mandatory.
\end{abstract}

\section{Background}

The prevalence of diabetes mellitus (DM) is rising worldwide and is more in the developing countries which unfortunately are already suffering from communicable diseases [1]. It is estimated that over $70 \%$ of people with diabetes will reside in developing countries by the year $2030[2,3]$.

Up about $85 \%$ to $95 \%$ of all diabetes in high-income countries is type II diabetes and may account for an even higher percentage in low- and middle-income countries [4]. Type II DM became a very common and serious global health problem, which, for most countries, is associated with rapid cultural and social changes, ageing populations, increasing urbanization, dietary changes, reduced physical activity, and other unhealthy behaviors $[5,6]$.

In African region only an estimated USD 2.8 billion was spent on healthcare expenditure due to diabetes in 2011 [7].
Reports are expecting the expenditure to rise by $61 \%$ by 2030 ; meanwhile the prevalence of diabetes is expected to almost double in the same time period [7].

Despite its devastating effect on the health of individuals, people with type II diabetes may remain unaware of their illness for a long time because symptoms may take years to appear or be recognized, during which time the body is being damaged by excess blood glucose [5]. Despite the presence of effective medical treatments for diabetes, a very large number of diabetic patients die every year in Ethiopia [8]. The problem of nonadherence to medical treatment remains a challenge for the medical professions and social scientists. As a result, significant numbers of patients are not adequately benefited from medical treatment, which in turn end up with poor health outcomes, lower quality of life, and increased health care costs. Despite the advancement 
in adherence research, nonadherence rates have remained nearly unchanged in the last decades $[9,10]$.

Generally, diabetes care is provided at general outpatient clinics or hospitals. The Ethiopian Diabetes Association has tried to share its part in diabetes prevention, care, and treatment [8]. Despite the fact that diabetic care is provided as an outpatient service in Ethiopia, adhering to their medication is still difficult in type II diabetic patients. In Ethiopia, particularly in the study area, little is known about the adherence status and associated factors. Therefore, the aim of this study was to assess the adherence status and associated factors to antidiabetic therapy among patients on follow-up at University of Gondar Hospital diabetic clinic.

\section{Methods}

2.1. Study Design and Period. An institution based crosssectional study was conducted from March 1 to June 30, 2013.

2.2. Study Area. This study was conducted at University of Gondar Hospital, Diabetic Clinic, Gondar, Northwest Ethiopia. Gondar town is located in Northern part of Ethiopia in Amhara region, $748 \mathrm{~km}$ far from the capital city, Addis Ababa.

Gondar College of Medicine and Health Sciences (CMHS) is the oldest medical school in Ethiopia established as the Public Health College in 1954. It is a tertiary level teaching and referral hospital, which acts as the referral centre for four district hospitals in the area.

Diabetic Clinic in University of Gondar teaching and referral hospital was established in 1985 and proper documentation and registration was started 20 years ago. The clinic is giving service to 3029 registered DM patients and among these 1497 are type II.

\subsection{Operational Definition}

2.3.1. Adherence. The extent to which a person's behavior taking antidiabetic medication corresponds with agreed recommendations from a health care provider [11].

2.3.2. Adherent. Those patients who scored $<3$ from the 5-point response Morisky Medication Adherence Scale (MMAS) [12].

2.3.3. Nonadherent. Those patients who scored $\geq 3$ from the 5-point response Morisky Medication Adherence Scale (MMAS) [12].

2.3.4. Knowledgeable. Respondents who scored points at mean and above for the knowledge questions prepared on DM and its medication would be referred to be knowledgeable or otherwise not [13].

2.3.5. Positive Attitude. Respondents who scored points at mean and above for the attitude questions prepared on DM and its medication would be referred to be with positive attitude or otherwise not [13].

2.3.6. Good Patient-Provider Relationship. Participants scored at mean and above for questions prepared on patient provider relationship in the treatment and care of DM patients [13].

2.4. Sample Size Calculation. It was assumed that the precision to an acceptable approximation of the population has been taken to be $95 \%$ with a difference of no more than $5 \%$ from the actual figures in the source population. From the previous study, proportion was used as $78.4 \%$ [14]. Based on this assumption, the required sample size was 288 by adding $10 \%$ nonresponse rate.

2.5. Sampling Technique. Systematic sampling method was used to select the sample of the participants of the study. There was a total of 1497 registered type II diabetic patients who were on antidiabetic medication and at follow-up care in GUH. Sampling interval $(K)$ was determined by dividing the number of units in the population by the desired sample size: that is, $K=1497 / 288=5$. Thus every other 5 patients were interviewed when they came for follow-up care at the diabetic clinic during the study period.

2.6. Data Collection Procedures. Data were collected using structured interview. The questionnaire for the interview has had three sections: sociodemographic, adherence, and factors associated with adherence. The independent variables to explain the medication adherence included patient related factors, health system factors, provider factors, and social factors. Adherence was measured using the standardized and widely utilized four-item Morisky Medication Adherence Scale (MMAS-4). The questionnaire was prepared in English version and it was translated back to Amharic and again to English to confirm the consistency of the translation. Twelve 4th year nursing students and two nurses were involved in the data collection. There were two B.S. Nurse Supervisors. The data were collected from March 1 to June 30, 2013.

2.7. Data Processing and Analysis. Data were checked, sorted, categorized, and coded. After coding the data were entered to the computer to make it ready for processing and analysis. It was analyzed by using the SPSS version 20 software.

Descriptive statistics were used to illustrate the means, standard deviations, and frequencies of the study variables. Bivariate analysis was computed and those variables whose $p$ values were less than or equal to 0.2 were fitted into multiple logistic regression model. Odds ratios with $95 \%$ confidence interval were used to determine the strength of association between dependent and independent variables. $p$ values less than or equal to 0.05 were considered as statistically significant.

For analysis of adherence, a cut-off value of MMAS mean score $<3$ and $\geq 3$ was used for labeling patients as adherent or nonadherent, respectively. Morisky Medication Adherence Scale (MMAS), a 4-item questionnaire with a high reliability and validity, which has been particularly useful in chronic conditions such as diabetes was used. The scale is scored 1 point for never, 2 points for rarely, 3 points for some times, 4 points for often, and 5 points for always.

2.8. Ethical Considerations. The ethical clearance was obtained from the ethical review board of University of 
Gondar. An official letter was obtained from the department of nursing and was communicated to University of Gondar Hospital Diabetic Clinic. The participants were asked to be involved in the study voluntarily. The data were collected only after they have given their consents to participate. To secure the privacy of participants, they were guaranteed for confidentiality and they were assured that identifying information will not be made available to anyone who is not directly involved. Till research accomplishment the questionnaires were kept in a well secured cabinet. After the research defense and final work is approved by the department and then academic commission or/and University senate the original questionnaire for the data will be incinerated in a secured manner.

\section{Results}

3.1. Sociodemographic Characteristics. A total of 288 diabetes patients were involved in this study. The response rate was $100 \%$. Among the total of 288 respondents, 111 (38.5\%) and 177 (61.5\%) were males and females, respectively. The mean age was 55.2 (SD 10.966) years. Majority, 272 (94.4\%) and 256 (88.9\%), of the respondents were Amhara and Orthodox, respectively. One hundred sixty-nine (58.7\%) were married. Ninety-eight (34\%) had certificate and above while seventytwo $(25 \%)$ cannot read and write. Majority, 98 (34\%), of the participants were housewives and government employee, $50(17.4 \%)$. The mean average monthly income was 1231.02 (SD 1344.580) ET Birr. Large proportion, 240 (83.3\%), were Urban with their residence. One hundred fifty-seven (54.5\%) took below half an hour for a single trip to arrive at hospital (Table 1).

3.2. Medication Adherence. Majority, 245 (85.1\%), of the respondents were adherent (Figure 1).

3.3. Clinical and Medication Characteristics of Respondents. One hundred eighty-one (62.8\%) of the respondents were treated with oral hypoglycemic agents (OHAs) only. Majority 190 (66\%) and 175 (60.8\%) had been 3 years and more since medically diagnosed and treated for diabetes, respectively. The mean duration since being medically diagnosed with diabetes was 63.69 (SD 54.754) months. Majority, 143 (49.7\%), had been taking two types of drugs and the mean number of tablets taken per day was 3.33 (1.638). Frequency of daily dose and number of comorbidity section of the responses indicated that 170 (59\%) would have been taking their medications three times or more a day and 119 (41.3\%) of the respondents had one comorbidity. As to the cost of medication, $56.6 \%$ were buying their medication by themselves and $37.5 \%$ of the respondents were getting their medication for free. Regarding alcohol use, more than half of them (59\%) did not use alcohol (Table 2).

3.4. Knowledge and Attitude on Diabetes. Most of the respondents, 243 (84.4\%), were knowledgeable on diabetes and its medication. And large proportion, 220 (76.4\%), of them had positive attitude towards diabetes (Table 3 ).
TABLE 1: Sociodemographic characteristic of the study participants ( $n=288)$, GUH, Northwest Ethiopia, 2013.

\begin{tabular}{|c|c|c|}
\hline Variables & Frequency & Percent (\%) \\
\hline \multicolumn{3}{|l|}{ Sex } \\
\hline Male & 111 & 38.5 \\
\hline Female & 177 & 61.5 \\
\hline \multicolumn{3}{|l|}{ Age (years) } \\
\hline $18-40$ & 31 & 10.8 \\
\hline $41-59$ & 173 & 60.1 \\
\hline$\geq 60$ & 84 & 29.2 \\
\hline \multicolumn{3}{|l|}{ Ethnicity } \\
\hline Amhara & 272 & 94.4 \\
\hline Tigrie & 10 & 3.5 \\
\hline Other & 6 & 2.1 \\
\hline \multicolumn{3}{|l|}{ Religion } \\
\hline Orthodox & 256 & 88.9 \\
\hline Muslim & 24 & 8.3 \\
\hline Other & 8 & 2.7 \\
\hline \multicolumn{3}{|l|}{ Marital status } \\
\hline Unmarried & 15 & 5.2 \\
\hline Married & 169 & 58.7 \\
\hline Divorced & 38 & 13.2 \\
\hline Widowed & 66 & 22.9 \\
\hline \multicolumn{3}{|l|}{ Educational status } \\
\hline Cannot read and write & 72 & 25.0 \\
\hline Grades 1-6 & 46 & 16.0 \\
\hline Grades $7-12$ & 72 & 25.0 \\
\hline Certificate and above & 98 & 34.0 \\
\hline \multicolumn{3}{|l|}{ Employment status } \\
\hline Government & 50 & 17.4 \\
\hline Merchant & 37 & 12.8 \\
\hline Student & 1 & 0.3 \\
\hline Housewife & 98 & 34.0 \\
\hline Farmer & 20 & 6.9 \\
\hline Retired & 39 & 13.5 \\
\hline Other & 43 & 14.9 \\
\hline \multicolumn{3}{|l|}{ Monthly income } \\
\hline$<500 \mathrm{ETB}$ & 103 & 35.8 \\
\hline 500-999 ЕТВ & 63 & 21.9 \\
\hline$\geq 1000 \mathrm{ETB}$ & 122 & 42.4 \\
\hline \multicolumn{3}{|l|}{ Residence } \\
\hline Urban & 240 & 83.3 \\
\hline Rural & 48 & 16.7 \\
\hline \multicolumn{3}{|c|}{ Distance from the hospital (a trip) } \\
\hline$<0.5$ hours & 157 & 54.5 \\
\hline$\geq 0.5$ hours & 131 & 45.5 \\
\hline
\end{tabular}

3.5. Reasons for Nonadherence. For the respondents who could not adhere to their antidiabetic medications, most common reasons adduced for this scenario include the following: being busy 96 (33.3\%) and forgetfulness 93 (32.3\%) followed by being away from home $85(29.5 \%)$ and holiday 33 (11.5\%) (Figure 2). 


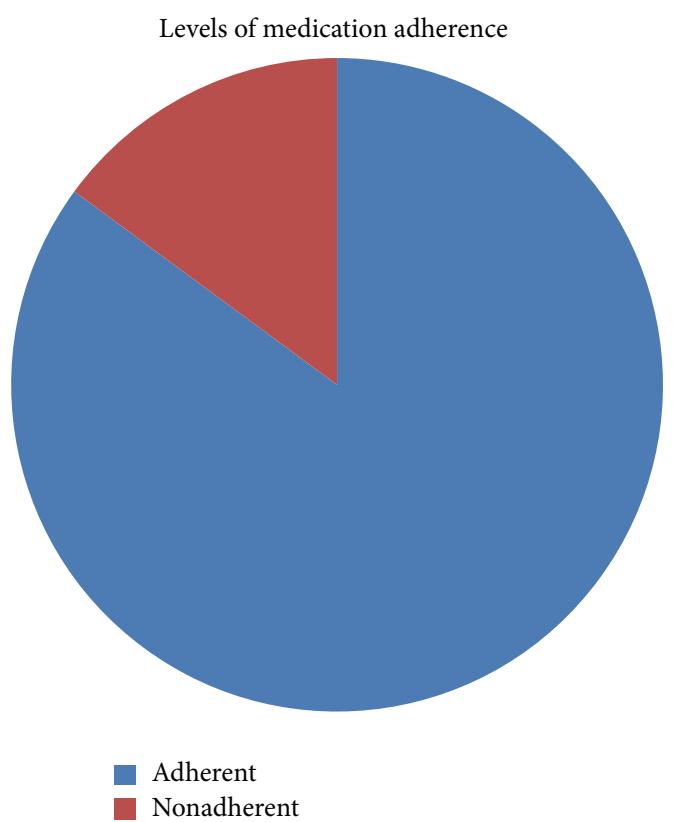

FIGURE 1: Respondents' level of adherence towards antidiabetic medications among type II diabetic patients in GUH, Diabetic Clinic, Northwest Ethiopia, 2013.

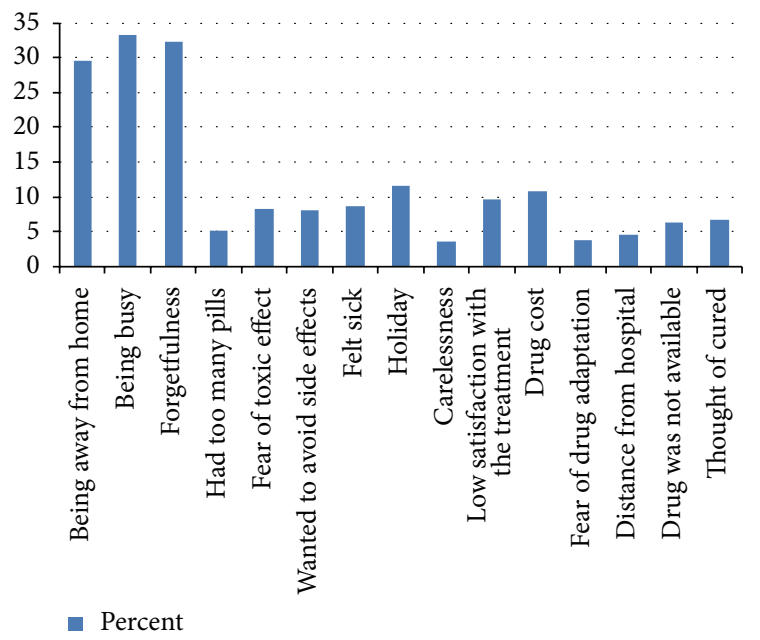

FIGURE 2: Respondents reasons for nonadherence towards antidiabetic medications, GUH, Northwest Ethiopia, 2013.

3.6. Factors Associated with Antidiabetic Medication. Variables considered in the bivariate analysis were sex, age, ethnic group, religion, marital status, educational status, occupation, monthly income, place of residence, distance from followup, duration of diabetes, duration of treatment, type of treatment, number of tablets, number of drugs, frequency of daily dose, number of comorbidity, coverage of drug cost, alcohol use, knowledge on diabetes, attitude towards diabetes, and patient-provider relationship. Variables with $p$ value $\leq 0.2$ were included in the multiple logistic regressions. At last educational status, occupation, duration of diabetes, and knowledge on diabetes remained to be significantly associated with adherence to antidiabetic medications.
TABLE 2: Clinical and medication characteristic of respondents, GUH, Northwest Ethiopia, 2013.

\begin{tabular}{|c|c|c|}
\hline Variables & Frequency & Percent \\
\hline \multicolumn{3}{|l|}{ Duration of DM (yrs) } \\
\hline $1 / 12-3$ & 98 & 34.0 \\
\hline$\geq 3$ & 190 & 66.0 \\
\hline \multicolumn{3}{|c|}{ Duration of treatment (yrs) } \\
\hline $1 / 12-3$ & 113 & 39.2 \\
\hline$\geq 3$ & 175 & 60.8 \\
\hline \multicolumn{3}{|l|}{ Type of treatment } \\
\hline $\mathrm{OHA}$ & 181 & 62.8 \\
\hline $\mathrm{OHA}+$ insulin & 44 & 15.3 \\
\hline Insulin & 63 & 21.9 \\
\hline \multicolumn{3}{|l|}{ Number of tablets/day } \\
\hline$\leq 2$ & 105 & 36.5 \\
\hline$>2$ & 183 & 63.5 \\
\hline \multicolumn{3}{|l|}{ Number of drugs } \\
\hline Monotherapy & 142 & 49.3 \\
\hline Two drugs & 143 & 49.7 \\
\hline Three or more drugs & 3 & 1.0 \\
\hline \multicolumn{3}{|l|}{ Frequency of daily dose } \\
\hline once & 25 & 8.7 \\
\hline BID & 93 & 32.3 \\
\hline TID or more & 170 & 59.0 \\
\hline \multicolumn{3}{|l|}{ Number of comorbidities } \\
\hline None & 122 & 42.4 \\
\hline One & 119 & 41.3 \\
\hline Two & 42 & 14.6 \\
\hline Three or more & 5 & 1.7 \\
\hline \multicolumn{3}{|c|}{ Who pays for medications } \\
\hline Self & 163 & 56.6 \\
\hline Family & 12 & 4.2 \\
\hline Government/free & 108 & 37.5 \\
\hline Welfare/charity & 1 & 0.3 \\
\hline Employer & 4 & 1.4 \\
\hline \multicolumn{3}{|l|}{ Alcohol use } \\
\hline Never & 170 & 59.0 \\
\hline Sometimes & 110 & 38.2 \\
\hline Often & 6 & 2.1 \\
\hline Always & 2 & 0.7 \\
\hline
\end{tabular}

TABLE 3: Respondents' knowledge and attitude towards DM and its medication, GUH, Northwest Ethiopia, 2013.

\begin{tabular}{lcc}
\hline Variables & Frequency & Percent $(\%)$ \\
\hline Knowledge level & & \\
Knowledgeable & 243 & $\mathbf{8 4 . 4}$ \\
Not knowledgeable & 45 & 15.6 \\
Attitude level & & \\
Good attitude & 220 & $\mathbf{7 6 . 4}$ \\
Poor attitude & 68 & 23.6 \\
\hline
\end{tabular}

According to the result of the multivariate analysis, a shift from unable to read and write to grades 1-6th will increase the probability of antidiabetic medication adherence by $5.25(\mathrm{AOR}=5.25,95 \%, \mathrm{CI}=1.19,23.12)$. Similarly patients 
TABLE 4: Logistic regression output showing the impact of selected sociodemographic, clinical, and other characteristics on adherence to antidiabetic medications, GUH, Northwest Ethiopia, 2013.

\begin{tabular}{|c|c|c|c|c|}
\hline \multirow{2}{*}{ Variables } & \multicolumn{2}{|c|}{ Adherence status } & \multirow{2}{*}{ COR $(95 \%$ CI $)$} & \multirow{2}{*}{ AOR (95\% CI) } \\
\hline & Nonadherent & Adherent & & \\
\hline \multicolumn{5}{|l|}{ Educational status } \\
\hline Cannot read and write & 26 & 46 & 1 & 1 \\
\hline Grade 1-6th & 6 & 40 & $3.76(1.40,10.07)$ & $5.25(1.19,23.12)^{* *}$ \\
\hline Grade 7-12th & 8 & 64 & $4.52(1.87,10.88)$ & $2.64(0.64,10.86)$ \\
\hline Certificate and above & 3 & 95 & $17.89(5.14,62.21)$ & $14.27(3.0,67.82)^{* *}$ \\
\hline \multicolumn{5}{|l|}{ Residence } \\
\hline Urban & 26 & 214 & 1 & \\
\hline Rural & 17 & 31 & $0.22(0.10,0.45)^{*}$ & \\
\hline \multicolumn{5}{|l|}{ Type of treatment } \\
\hline OHA & 29 & 152 & 1 & \\
\hline $\mathrm{OHA}+$ insulin & 9 & 35 & $0.74(0.32,1.70)$ & \\
\hline Insulin & 5 & 58 & $2.21(0.81,5.99)^{*}$ & \\
\hline \multicolumn{5}{|l|}{ Dosage frequency } \\
\hline Once daily & 9 & 16 & 1 & \\
\hline BID & 13 & 80 & $3.46(1.26,9.45)^{*}$ & \\
\hline TID and above & 21 & 149 & $3.99(1.26,10.7)^{*}$ & \\
\hline \multicolumn{5}{|l|}{ Duration of diabetes } \\
\hline$<3$ years & 35 & 63 & 1 & 1 \\
\hline$\geq 3$ years & 8 & 182 & $12.63(5.56,28.69)$ & $6.10(2.03,18.34)^{* *}$ \\
\hline \multicolumn{5}{|l|}{ Duration of treatment } \\
\hline$<3$ years & 37 & 76 & 1 & \\
\hline$\geq 3$ years & 6 & 169 & $13.71(5.55,33.86)^{*}$ & \\
\hline \multicolumn{5}{|l|}{ Number of tabs per day } \\
\hline$\leq 2$ & 20 & 85 & 1 & \\
\hline$>2$ & 23 & 160 & $1.63(0.85,3.14)^{*}$ & \\
\hline \multicolumn{5}{|c|}{ Knowledge towards DM and medications } \\
\hline Not knowledgeable & 31 & 14 & 1 & 1 \\
\hline Knowledgeable & 12 & 231 & $42.62(18.08,100.4)$ & $28.05(8.96,87.8)^{* *}$ \\
\hline \multicolumn{5}{|c|}{ Attitude towards DM and medications } \\
\hline Negative & 17 & 51 & 1 & \\
\hline Positive & 26 & 194 & $1.43(0.15,13.15)^{*}$ & \\
\hline
\end{tabular}

${ }^{*}$ Variables that were significant during bivariate logistic analysis at $p$ value $\leq 0.2$ but were not significant by backward multivariate logistic regression analysis at $p$ value below 0.05 .

${ }^{* * *}$ Variables that were found to have significant association both during bivariate and multivariate analysis at $p$ value $\leq 0.2$ and $<0.05$, respectively.

with educational level of certificate and above were 14 times more likely to be adherent with medications than those who cannot read and write $(\mathrm{AOR}=14.27,95 \% \mathrm{CI}=3.0,67.82)$. Individuals with three years and more since being medically diagnosed with diabetes were 12 times more likely to be adherent to their medications than patients with less than three years' duration $(\mathrm{AOR}=6.10,95 \% \mathrm{CI}(2.03,18.34))$. Regarding knowledge, the analysis showed that clients who are knowledgeable about diabetes and its medications were about 28 times more probably to be adherent to antidiabetic medications $(\mathrm{AOR}=28.05,95 \%$, CI $(8.96,87.8)($ Table 4$))$.

\section{Discussions}

Ensuring patients' adherence to antidiabetes medications to prevent complications of diabetes remains a major challenge to public health in many developing countries. Nonadherence to medication is potentially one of the most serious problems facing diabetes care delivery, particularly in type 2 diabetes. Poor adherence to medications is the most important single reason for uncontrolled diabetes, serious complications, and wastage of health care resources $[15,16]$. This study tried to identify factors associated with adherence to antidiabetes medications.

Adherence with antidiabetic medications in this study $(85.1 \%)$ was higher than the earlier finding in New York (72\%) [17], Malaysia (66\%) [18], Iran (74.8\%) [19], Nigeria (72.5\%) [20], and Uganda (71\%) [21]. The discrepancy is possibly because of time gap, the age limit of participants enrolled, differences in source population, and medication adherence measurement method. The age limit and knowledge (Malaysia) and the participants enrolled in a study done 
in Iran were randomly selected from eight healthcare centers (Iran); the level of medication adherence measured was based on patients' blood glucose record (Nigeria) and pill count (Uganda) in addition to self-report.

On the other hand the prevalence of antidiabetic medication adherence of the current study was comparable with that of studies done in Palestine (83.1\%) [10] and Brazil (78.3\%) [22]. This could be because both studies used a similar measurement of medication adherence level as the present study. Similarly the finding of a study conducted in Harari [14] revealed that $78.4 \%$ of the respondents were adherent with the prescribed medications which are in line with the current study. This could be explained by the similarity of the sociodemographic and healthcare system of the participants.

In this study significant association between educational level and adherence level was observed. Accordingly patients with certificate and above educational level were more adherent than with unable to read and write individuals. This finding is in line with a study done in Brazil [22], Malaysia [18], Isfahan-Iran [23], and India [24]. A study done in Uganda [21] and Harari [14] also supports the finding of this current study. Individuals with elementary educational status were more likely to be adherent than unable to read and write individuals. The possible justification of this could be the fact that educational level is the most important predictor of knowledge of patients. Low schooling makes learning more difficult; as diabetes drug therapy gets more complex, patients are required to have more complex cognitive skills to be able to understand the prescribed drug therapy and to adhere to treatment for good glucose control.

Duration of diabetes was another variable found to be significantly associated with the adherence status of the respondents. Those patients who had been three years and above since medically diagnosed with diabetes were more likely to be adherent than those with less than three years of duration. This finding is in agreement with the study done in Malaysia [18], Urmia, Iran (AOR = 3.6, 95\% CI: 2.1, 5.7) [19], and Nigeria [20]; patients who had been diabetic for 3 years and above are more adherent than less than 3 years. This could be explained by patients with longer duration of diabetes by virtue of their frequent contacts with health facilities and health professionals are more likely to be given repetitive instruction on medication adherence and become aware of the acute and chronic complications of uncontrolled blood glucose. In addition, it could be a reflection of wider social interaction with other diabetic patients on antidiabetic medication adherence.

Knowledge towards DM and its medications was found to be positively associated to the adherence level of patients. This finding is in line with studies done in Malaysia [18], Harari [14], and Palestine [25] where knowledgeable patients were found to be significantly associated with a higher adherence rate. The possible justification of why people with better knowledge were adherent could be the right knowledge about DM and its medications creates a clear understanding and avoids confusion about the treatment and the disease condition. But people with wrong/poor knowledge may reach with wrong decisions. Knowledge of patients has an impact on diabetic patients' adherence to antidiabetic medications in health care settings.

\section{Conclusions}

The overall adherence towards antidiabetic medications in this study was high. Educational status, duration of diabetes, and knowledge towards DM and its medications were significantly associated with antidiabetic medication adherence of patients. Unable to read and write, a duration of less than three years since medically diagnosed for diabetes, and being not knowledgeable were factors associated with nonadherence to antidiabetic medication.

\section{Conflict of Interests}

The authors declare that they have no competing interests.

\section{Authors' Contribution}

Mastewal Abebaw, Anteneh Messele, and Mignote Hailu were involved in the design of the study, data analysis, and interpretation of the findings, report writing, and paper preparation. Fisseha Zewdu was involved in the design of the study, analysis and interpretation of the data, and review of the report. All authors read and approved the final paper. Mastewal Abebaw, Anteneh Messele, Mignote Hailu, and Fisseha Zewdu contributed equally to this work.

\section{Acknowledgments}

The authors' heartfelt thank goes to University of Gondar for all expenses of the research work and all the study participants who voluntarily participated in this study.

\section{References}

[1] A. O. Ogbera and S. F. Kuku, "Insulin use, prescription patterns, regimens and costs-a narrative from a developing country," Diabetology \& Metabolic Syndrome, vol. 4, no. 1, article 50, 2012.

[2] S. E. Inzucchi, Diabetes Facts and Guidelines, Yale Diabetes Center, 2011.

[3] J. E. Shaw, R. A. Sicree, and P. Z. Zimmet, "Global estimates of the prevalence of diabetes for 2010 and 2030," Diabetes Research and Clinical Practice, vol. 87, no. 1, pp. 4-14, 2010.

[4] T. Nigatu, "Epidemiology, complications and management of diabetes in Ethiopia: a systematic review," Journal of Diabetes, vol. 4, no. 2, pp. 174-180, 2012.

[5] D. L. Kasper, A. S. Fauci, D. L. Longo, E. Braunwald, S. L. Hauser, and J. L. Jameson, Harrison's Principles of Internal Medicine, McGraw-Hill, New York, NY, USA, 16th edition, 2012.

[6] S. C. Smeltzer, B. G. Bare, J. L. Hinkle, and K. H. Cheever, Brunner \& Suddarth's Textbook of Medical-Surgical Nursing, Lippincott Williams \& Wilkins, Philadelphia, Pa, USA, 12th edition, 2010.

[7] International Diabetes Federation, The Diabetes Atlas, International Diabetes Federation, Brussels, Belgium, 5th edition, 2011.

[8] Ethiopian Diabetes Association, Adama, Ethiopia, 2009, http://www.diabetesethiopia.org.et/. 
[9] J. A. Cramer, "A systematic review of adherence with medications for diabetes," Diabetes Care, vol. 27, no. 5, pp. 1218-1224, 2004.

[10] R. M. Jamous, W. M. Sweileh, A. S. Abu-Taha, A. F. Sawalha, S. H. Zyoud, and D. E. Morisky, "Adherence and satisfaction with oral hypoglycemic medications: a pilot study in Palestine," International Journal of Clinical Pharmacy, vol. 33, no. 6, pp. 942-948, 2011.

[11] N. T. Wabe, M. T. Angamo, and S. Hussein, "Medication adherence in diabetes mellitus and self management practices among type-2 diabetics in Ethiopia," North American Journal of Medical Sciences, vol. 3, no. 9, pp. 418-423, 2011.

[12] D. E. Morisky, L. W. Green, and D. M. Levine, "Concurrent and predictive validity of a self-reported measure of medication adherence," Medical Care, vol. 24, no. 1, pp. 67-74, 1986.

[13] A. D. Ambaw, G. A. Alemie, S. M. Wyohannes, and Z. B. Mengesha, "Adherence to antihypertensive treatment and associated factors among patients on follow up at University of Gondar Hospital, Northwest Ethiopia," BMC Public Health, vol. 12, article 282, 2012.

[14] K. Ayele, B. Tesfa, L. Abebe, T. Tilahun, and E. Girma, "Self care behavior among patients with diabetes in harari, eastern ethiopia: the health belief model perspective," PLOS ONE, vol. 7, no. 4, Article ID e35515, 2012.

[15] A. Khan, Z. Al-Abdul Lateef, M. Al Aithan, M. Bu-Khamseen, I. Al Ibrahim, and S. Khan, "Factors contributing to noncompliance among diabetics attending primary health centers in the Al Hasa district of Saudi Arabia," Journal of Family \& Community Medicine, vol. 19, no. 1, pp. 26-32, 2012.

[16] L. E. García-Pérez, M. Álvarez, T. Dilla, V. Gil-Guillén, and D. Orozco-Beltrán, "Adherence to therapies in patients with type 2 diabetes," Diabetes Therapy, vol. 4, no. 2, pp. 175-194, 2013.

[17] D. M. Mann, D. Ponieman, H. Leventhal, and E. A. Halm, "Predictors of adherence to diabetes medications: the role of disease and medication beliefs," Journal of Behavioral Medicine, vol. 32, no. 3, pp. 278-284, 2009.

[18] M. S. Omar and K. L. San, "Diabetes knowledge and medication adherence among geriatric patient with type 2 diabetes mellitus," International Journal of Pharmacy and Pharmaceutical Sciences, vol. 6, no. 3, pp. 103-106, 2014.

[19] Z. Yekta, R. Pourali, M. R. Aghassi, N. Ashragh, L. Ravanyar, and M. Y. R. Pour, "Assessment of self-care practice and its associated factors among diabetic patients in urban area of Urmia, northwest of Iran," Journal of Research in Health Sciences, vol. 11, no. 1, pp. 33-37, 2011.

[20] I. G. U. Pascal, J. N. Ofoedu, N. P. Uchenna, A. A. Nkwa, and G.-U. E. Uchamma, "Blood glucose control and medication adherence among adult type 2 diabetic Nigerians attending a primary care clinic in under-resourced environment of eastern Nigeria," North American Journal of Medical Sciences, vol. 4, no. 7, pp. 310-315, 2012.

[21] J. N. Kalyango, E. Owino, and A. P. Nambuya, "Non-adherence to diabetes treatment at mulago hospital in Uganda: prevalence and associated factors," African Health Sciences, vol. 8, no. 2, pp. 67-73, 2008.

[22] H. T. Gimenes, M. L. Zanetti, and V. J. Haas, "Factors related to patient adherence to antidiabetic drug therapy," Revista LatinoAmericana de Enfermagem, vol. 17, no. 1, pp. 46-51, 2009.

[23] S. Farsaei, A. M. Sabzghabaee, A. H. Zargarzadeh, and M. Amini, "Adherence to glyburide and metformin and associated factors in type 2 diabetes in Isfahan, Iran," Iranian Journal of Pharmaceutical Research, vol. 10, no. 4, pp. 933-939, 2011.
[24] S. Mukherjee, B. Sharmasarkar, K. K. Das, A. Bhattacharyya, and A. Deb, "Compliance to anti diabetic drugs: observations from the diabetic clinic of a medical college in Kolkata," Journal of Clinical and Diagnostic Research, vol. 7, no. 4, pp. 661-665, 2013.

[25] W. M. Sweileh, S. H. Zyoud, R. J. Abu Nab’A et al., "Influence of patients' disease knowledge and beliefs about medicines on medication adherence: findings from a cross-sectional survey among patients with type 2 diabetes mellitus in Palestine," BMC Public Health, vol. 14, no. 1, article 94, 2014. 


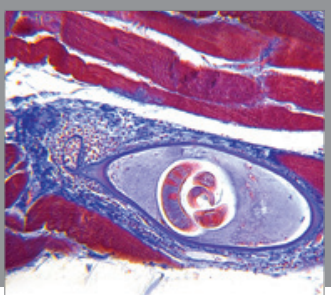

Gastroenterology

Research and Practice
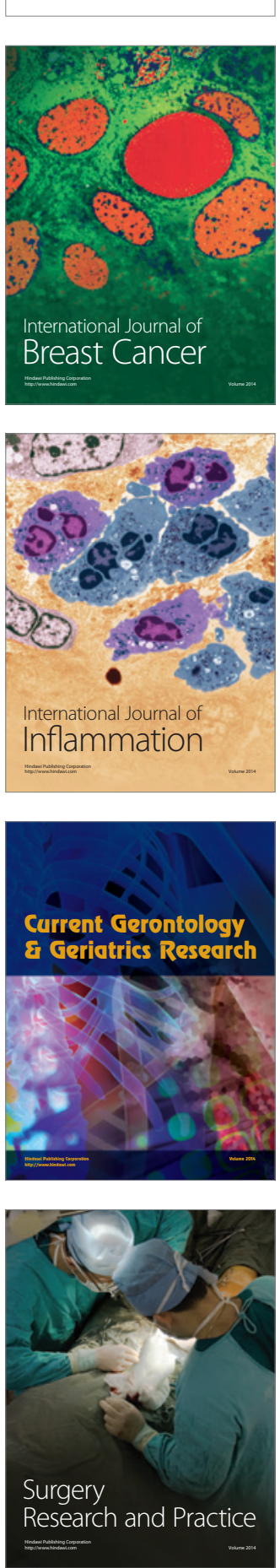

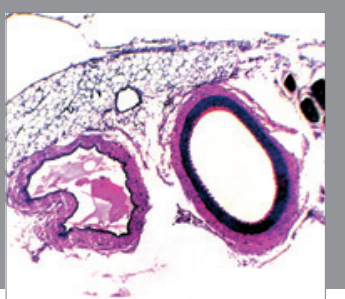

International Journal of Hypertension
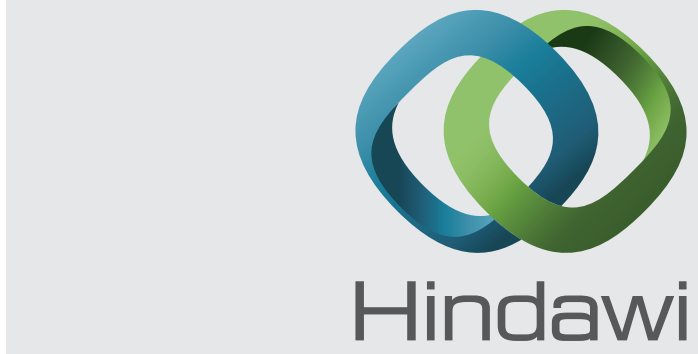

Submit your manuscripts at http://www.hindawi.com
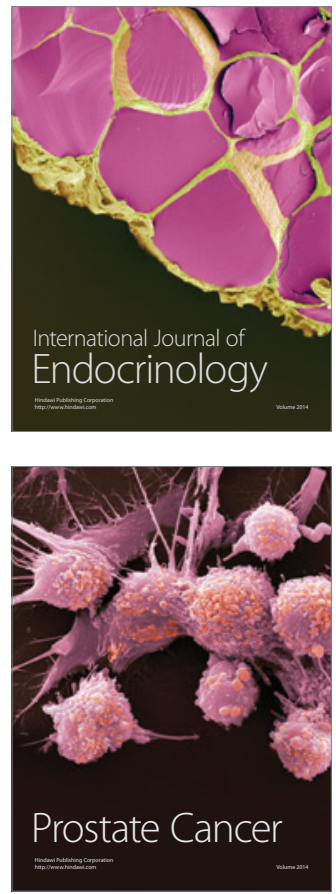

The Scientific World Journal
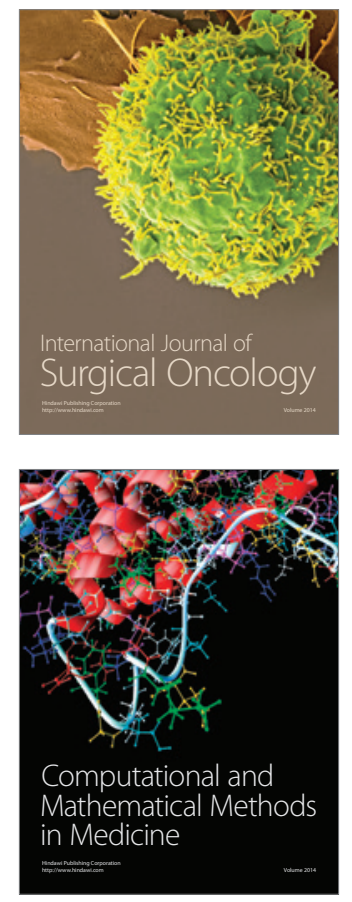
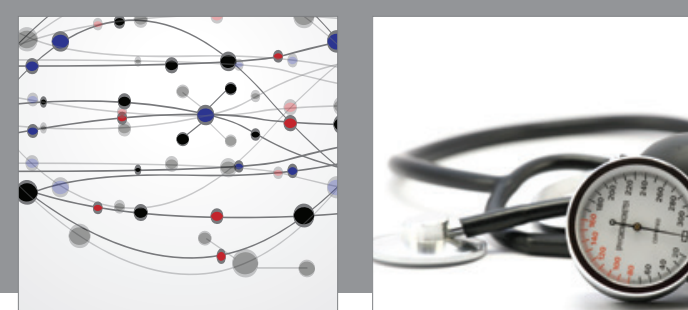

Nursing

Research and Practice

Research and Practice
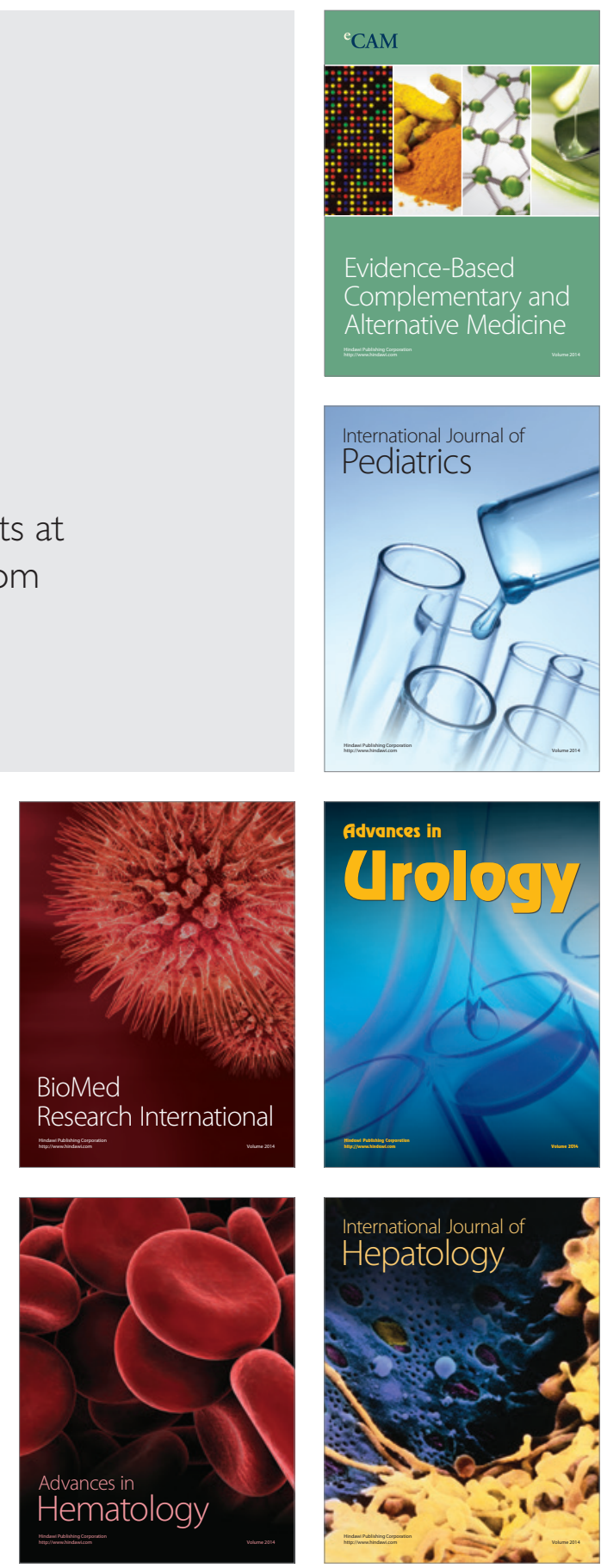
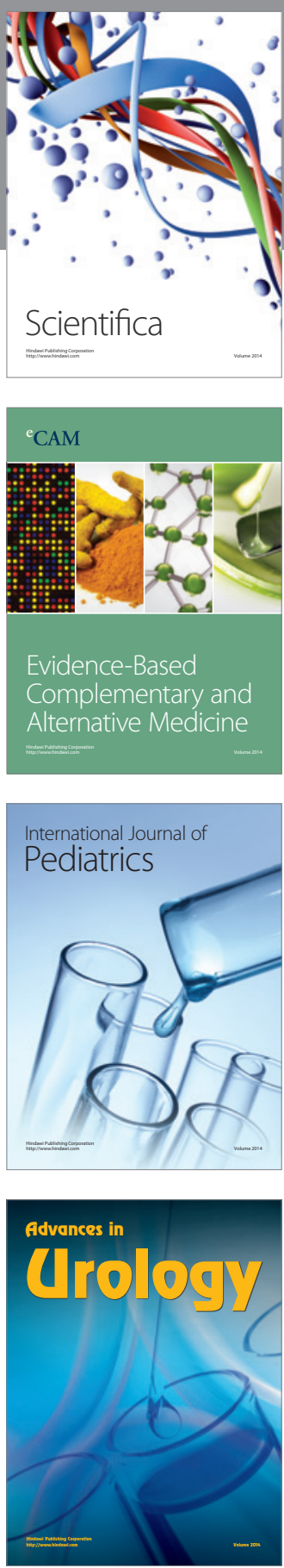

Scientifica

Evidence-Based

Complementary and

Alternative Medicine

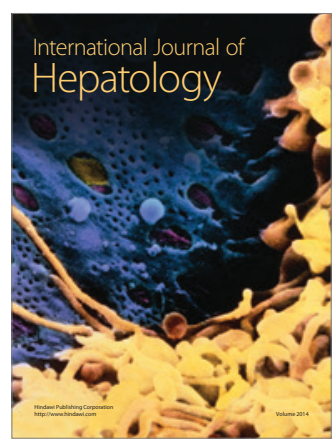

